\title{
A FAMÍLIA NA REDE DE APOIO DA GESTANTE
}

\author{
THE FAMILY IN THE SUPPORT OF THE PREGNANT WOMAN
}

Maria Alice Tsunechiro ${ }^{1}$

Isabel Cristina Bonadio ${ }^{1}$

RESUMO: Trata-se de um estudo preliminar que focaliza a família e ou seus membros na rede de apoio de gestantes. Foram entrevistadas 30 gestantes atendidas no serviço de pré-natal de uma instituição filantrópica da cidade de São Paulo, em fevereiro de 1997. A instituição atende prioritariamente mulheres socialmente desamparadas. Os dados foram coletados utilizando-se um formulário específico e analisados em função de freqüência absoluta e relativa e, quando pertinentes de forma descritiva. As gestantes caracterizavam-se por média de idade de 23,3 anos; prendas domésticas (43,3\%); com primeiro grau incompleto ( $86,7 \%$ ); mãe e pai vivo ( $73,3 \%$ e $60,0 \%$ respectivamente); $63,4 \%$ provenientes de família com quatro ou mais irmãos. Tinham convívio parental $83,3 \%$ das gestantes, sendo $63,3 \%$ com o marido ou companheiro, enquanto $16,7 \%$ viviam fora do contexto familiar. Como provedores de apoio, foram reconhecidos pela gestante, o marido ou pai da criança e outros parentes consangüíneos bem como pessoas não pertencentes ao contexto familiar. Concluise que os membros da família ocupam espaço na rede de apoio da maioria das gestantes. Quanto ao apoio esperado após o parto, no entanto, as respostas de algumas gestantes eram carregadas de emoção, mostrando a necessidade de serem acolhidas e reconhecidas pela família. Assim, sugere-se estudos com outras abordagens metodológicas, para elucidar com mais clareza, o apoio familiar no processo gravídico-puerperal.

PALAVRAS CHAVE: Relações familiares; Família; Saúde da mulher.

\section{INTRODUÇÃO}

A gravidez, apesar de constituir evento biologicamente natural, é especial na vida da mulher e como tal, desenvolve-se dentro de um contexto social e cultural que influencia e determina a evolução da gravidez bem como a sua assistência.

O ciclo grávido-puerperal acarreta grandes modificações não apenas corporais, como na maneira de ser da mulher e em suas relações pessoais, constituindo-se em período de transição existencial das mais importantes. Para todas as pessoas, independente do nível educacional ou sócio-cultural, as vivências deste período são semelhantes, estando as diferenças condicionadas ao cenário da gravidez, desejada ou indesejada; primeiro ou segundo filho; com ou sem vínculo estável entre o homem e a mulher ou entre familiares e amigos. Frente a tantas modificações e sensações, a mulher precisa do chão seguro de um vínculo de suporte e de confiança. (Maldonado; Canella, 1988)

$\mathrm{Na}$ nossa sociedade, as pressões sociais têm forte influência na maneira como a mulher vivencia a gravidez e a maternidade e, nesse contexto, o convívio em família representa condição básica para a existência do ser humano.

Como profissionais de enfermagem, integrantes de um grupo de docentes da área de Enfermagem O bstétrica, atuamos, há três décadas, em uma instituição filantrópica da cidade de São Paulo. Essa Instituição foi criada em 1939, para acolher e prestar assistência médico-social, prioritariamente, a mulheres grávidas solteiras abandonadas, ou mesmo com famílias completas, porém com dificuldades sócio-econômicas.

No início de suas atividades grande parte das mulheres acolhidas nessa Instituição eram solteiras, prostitutas ou pessoas que não possuíam famílias constituídas, sendo consideradas socialmente desajustadas. Esse fato, acrescido do forte preconceito existente contra essas mulheres, nas décadas de 50 e 60 , tornou a

Enfermeira Obstétrica. Professor Doutor do Departamento de Enfermagem Materno-Infantil e Psiquiátrica da Escola de Enfermagem da Universidade de São Paulo. 
Instituição fortemente estigmatizada sendo, até hoje, conhecida como "casa da mãe solteira". Em conseqüência, ainda na atualidade, muitas mulheres têm medo de serem estigmatizadas, caso necessitem atendimento nessa Instituição.

0 relato de algumas mulheres desamparadas que foram acolhidas pela Instituição na década de 50 , mostra que elas conseguiram reorganizar suas vidas e constituir novos núcleos familiares em função do apoio recebido, muitas delas como chefe de família. Destacaram o fato de terem sido respeitadas enquanto seres humanos e à percepção do espírito de família existente na referida Instituição como responsáveis pela reestruturação de suas vidas (Bonadio, 1996).

Atuando como profissionais de saúde nessa Instituição, percebemos que a despeito das grandes transformações da sociedade havida com o passar dos tempos, principalmente quanto ao incentivo para a luta pela conquista da cidadania, muitas mulheres e seus filhos ainda continuam à margem da sociedade. Parece que, ultimamente, tem havido mudança nessa clientela, havendo coexistência de mulheres com características sócio-econômicas, estrutura e dinâmica familiar diversas.

A consciência da importância do apoio social e familiar à mulher grávida, e a ausência de estudo com este enfoque sobre as mulheres atendidas nessa Instituição, foram os motivos para iniciarmos investigações quanto a inserção familiar da clientela atendida na presente época. Isso é necessário, uma vez que esse serviço tem sido utilizado como campo de ensino teórico-prático de estudantes de enfermagem, de medicina, de nutrição, de psicologia, entre outros. Os estudantes de enfermagem têm considerado que o contato com mulheres socialmente excluídas vem contribuindo significativamente para a sua formação profissional e pessoal (Bonadio, 1996).

Assim, torna-se necessário investigar as características dessa clientela pois percebemos que, embora atualmente tenha aumentado a demanda de mulheres com famílias constituídas, ainda mantém-se a grande freqüência daquelas com graves problemas sociais. A compreensão desse aspecto de vida da clientela atual poderá oferecer subsídios para o redirecionamento das atividades de extensão universitária e do ensino de enfermagem, visando fundamentalmente a qualidade da assistência e a produção de conhecimento em enfermagem obstétrica e da família.

\section{METODOLOGIA}

Trata-se de um estudo descritivo realizado no Amparo Maternal, instituição filantrópica, vinculada à Igreja Católica, localizada na cidade de São Paulo. Essa Instituição caracteriza-se pela sua atuação, principalmente no âmbito da assistência médica-hospitalar às mulheres no ciclo gravídico-puerperal e assistência social, acolhendo gestantes e o binômio mãe-recém-nascido, quando necessário, em sistema de Alojamento Social.

Foram entrevistadas 30 gestantes que freqüentavam o Ambulatório de P ré-Natal da Instituição, no mês de fevereiro de 1997. Foi utilizado um formulário estruturado com perguntas abertas e fechadas. As gestantes foram informadas sobre o objetivo do estudo e com a sua anuência, as entrevistas foram realizadas após a consulta pré-natal.

Os dados estão apresentados de forma descritiva, mediante freqüência absoluta e relativa.

\section{RESULTADOS E COMENTÁRIOS}

As gestantes tinham entre 14 e 36 anos de idade, estando a média em 23,3 anos. Ocupavam-se de atividades em sua própria casa 43,3\% das gestantes e, fora do lar 46,7\% (como doméstica, 30,0\% e no comércio e/ou indústria, $16,7 \%)$; três adolescentes eram estudantes. A maioria (86,7\%) tinha o primeiro grau incompleto, enquanto $13,3 \%$ das gestantes possuíam o segundo grau completo ou incompleto, perfazendo uma média de seis anos de escolaridade. Quanto ao número de filhos vivos $16(53,3 \%)$ não tinham nenhum, enquanto $14(46,7 \%)$ tinham de um a quatro filhos, dando uma média de 1,85 filhos por mulher, dentre aquelas que já eram mães.

Quanto à constituição da família de origem, a maioria tinha mãe $(73,3 \%)$ e pai $(60,0 \%)$ vivos, $63,4 \%$ eram provenientes de família com quatro ou mais irmãos, chegando a haver gestantes com mais de 10 irmãos; uma era filha única e três eram adotivas.

A maioria (83,3\%) das gestantes tinha convívio familiar, sendo $63,3 \%$ com o marido ou companheiro, $20,0 \%$ com parentes consangüíneos e $16,7 \%$ viviam fora do contexto familiar. Daquelas gestantes com convívio familiar, 50,0\% constituíam família nuclear, sendo que 23,3\% viviam apenas com o marido, enquanto $26,7 \%$ com marido e filhos. As outras gestantes conviviam em famílias extensas - 10,0\% moravam com o marido, 
filhos e outros parentes, 3,3\% com marido e parentes. As outras 20,0\% moravam com parentes como mãe, irmãos, avós, tios, irmãos casados. Das $16,7 \%$ que viviam fora do contexto familiar, $13,4 \%$ estavam acolhidas no Alojamento Social e uma (3,3\%) morava com amigas.

A maioria $(60,0 \%)$ das gestantes não havia planejado, mas 73,4\% desejavam a gravidez; assim sendo, $93,4 \%$ aceitaram a gravidez, embora inicialmente $10,0 \%$ destas a tenham rejeitado. Das duas gestantes que não estavam aceitando a gravidez, uma informou que iria deixar a criança na Instituição para adoção.

\section{Rede de apoio}

A pessoa que vivencia situação de transição existencial necessita de vínculo de suporte e confiança, que pode ser proveniente de pessoas que lhe sejam significativas e estejam disponíveis para oferecer-lhe suporte, pois isso Ihe proporcionará maior segurança no enfrentamento de dificuldades durante o processo grávido puerperal.

No presente estudo, o marido ou pai da criança foi citado pelas gestantes como aquele que ouve queixas, compartilha sentimentos, dá atenção $(63,4 \%)$; dá conselhos e esclarece dúvidas $(36,7 \%)$; e também como provedor de apoio financeiro $(60,0 \%)$. Além do marido ou do pai da criança a mãe, irmãs, irmãos, tias e outros parentes consangüíneos têm representatividade enquanto rede de apoio. Destacam-se a mãe e irmãs para dar conselhos e esclarecer dúvidas, provavelmente em função de experiência vivida. Assim, os membros da família foram reconhecidos pela maioria das gestantes como provedores desse suporte e ocupam grande espaço na rede de apoio da gestante, evidenciando que em nossa sociedade a família constitui núcleo básico e primário na vida das pessoas. Isso pode ter sido favorecido pelo fato de muitas delas possuírem famílias extensas.

As gestantes encontram suporte também fora do âmbito familiar, em amigas, vizinha, patroa, colegas de trabalho e outras gestantes, como no caso daquelas acolhidas no Alojamento Social.

Quanto ao acompanhamento para a consulta pré-natal ou para realizar exames durante a gravidez, $50,0 \%$ das gestantes informaram que sempre vão sozinhas. A companhia do marido é eventual, ocorrendo em apenas $13,3 \%$ das gestantes, comprovando a pouca participação ativa do homem no seu papel de pai. Algumas gestantes têm também, a companhia de filhos ou sobrinhos menores, mãe ou outros parentes. Essa companhia ocorre com mais freqüência no final da gestação, sendo alegado, pela própria gestante, que isto é feito como medida de precaução e de segurança para ela.

Após o parto, o apoio esperado pelas gestantes diz respeito ao cuidado do bebê e às atividades domésticas. A maioria delas, $80,1 \%$, referiu que contaria com ajuda após o parto, enquanto $13,3 \%$ disseram que não. 0 marido foi indicado por $30,0 \%$ das gestantes como aquele que dará o apoio, 23,3\% indicaram a mãe, 20,0\% a irmã, 26,6\% outros parentes consangüíneos, $6,6 \%$ pessoas afins como a sogra ou a cunhada e $3,3 \%$ provavelmente a vizinha. Uma das adolescentes de 16 anos, verbalizou incerteza quanto à sua situação após o parto, pois a decisão de ficar ou não com o filho caberia à sua mãe e ao padrasto; sua expressão facial denotava muita tristeza e chorou quando falou sobre seu futuro, alegou que ela era o motivo de muitas brigas entre sua mãe e o seu atual marido.

De acordo com Ferrari; Kaloustian (1994), a família, independentemente do arranjo ou estrutura, propicia os aportes afetivos e materiais necessários ao desenvolvimento e bem-estar dos seus componentes. É na família que encontra-se o espaço privilegiado de socialização, de prática de tolerância e divisão de responsabilidades, de busca coletiva de estratégias de sobrevivência e lugar inicial para o exercício da cidadania sob o parâmetro da igualdade, do respeito e dos direitos humanos. Considerando esses princípios, destacamos que $16,7 \%$ das gestantes que participaram do estudo, por não estarem inseridas em um contexto familiar, provavelmente enfrentarão dificuldades maiores para propiciar a seus filhos um espaço para a absorção de valores éticos e humanitários.

Mesmo para as gestantes que estão vivendo dentro de um contexto familiar, principalmente aquelas que não contam com a presença do pai do bebê, pela eventual e pouca participação do companheiro no acompanhamento para a consulta de pré-natal não percebe-se mudança do papel desempenhado pelo homem. Papel este pelo qual os homens, que em função das transformações pelas quais vêm passando as famílias na sociedade ocidental, hoje lutam para ter uma participação mais ativa dividindo com as mulheres as tarefas que o sistema social ainda coloca como exclusiva do gênero feminino, conforme descreve Ramires (1997). Para esse autor, atualmente observa-se uma grande riqueza na variação dos padrões familiares e a família nuclear burguesa está deixando de se constituir no modelo predominante. A progressão no número de divórcios, filhos 
criados pelo pai ou pela mãe, ou em famílias reconstituídas compõem os novos arranjos familiares. Como conseqüência, esses arranjos não comportam mais a simples reprodução dos antigos modelos para o exercício dos papéis de mãe e de pai.

O modelo de pai provedor, exercendo sua principal função no espaço público, distante dos filhos, representante da autoridade e da lei, mais temido do que respeitado e objeto de identificação idealizado, ainda é o predominante $(60,0 \%)$ na clientela de gestantes do Amparo assemelhando-se ao modelo consolidado como patrimônio da família nuclear burguesa ou patriarcal.

\section{CONSIDERAÇÕES FINAIS}

Apesar da maioria da clientela do Ambulatório de Pré-Natal do Amparo Maternal ter referido contar com apoio social e econômico da família e dos familiares é válido questionar se isso ocorre concretamente e como eles ocupam espaço na rede de apoio destas gestantes. 0 que nos leva a essa observação é a nossa vivência no Serviço que nos revela muitas mulheres com relações familiares extremamente conflituosas e em situação de abandono. Percebe-se relações conflituosas principalmente quando a gravidez ocorre entre homem e mulher sem qualquer vínculo significativo ou ainda no início de relacionamento afetivo. A situação de abandono ocorre quase sempre por parte do pai da criança em gestação, quando este não aceita a gravidez e, também quando os demais familiares não aceitam ou não as apoiam, obrigando-as a assumirem sozinha a maternidade. Além disso, reforça essa observação o fato de algumas gestantes, durante a entrevista, particularmente quando foi perguntado sobre o apoio esperado após o parto e o nascimento do filho, terem apresentado respostas carregadas de emoção, demonstrando a necessidade de serem acolhidas e reconhecidas pela família. Isto causou-nos sentimento de impotência e frustração. Neste trabalho inicial, não foi possível evidenciar claramente tais fatos, o que nos leva a dar continuidade ao estudo, ampliando a amostra pesquisada bem como utilizando outras abordagens metodológicas.

Nesse sentido, como afirmam Reeder et al (1978), Quintero Velásquez (1997) entre outros, para compreender e atender a multifatoriedade dos fenômenos que ocorrem na família, entendida como um processo articulado, dinâmico e de interação permanente é imperioso considerar a importância de trabalho interdisciplinar, dado que nenhuma disciplina ou profissão tem toda a bagagem cultural e metodológica para estudar e abordar sozinha a complexidade humana.

ABSTRACT: This is a preliminary study which focus on the family and or its members in the support of the pregnant women.There were interview 30 pregnant women who attended a prenatal clinic in a filantrophic institution in the city of São Paulo, in February of 1997. The institution shelters and assists poor women. The data was collected through a questinnaire which were analysed and presented as absolute and relative frequency and when appropriate were described. Their profile show that: the average age of women was 23,3; housewives $(43,3 \%)$; low level of education and provinent of a family more than four members. The husband and close relatives were recognized by the women as source of support. About the support expected after the delivery the answeres of the pregnant women were very emotional, showing the need to be held and accepted in the family. Further studies with other methodology are suggested to get a deepen knowledge on the topic.

KEY WORDS: Family relations; Family; Woman's health.

\section{REFERÊNCIAS BIBLIOGRÁFICAS}

1. BONADIO, I.C. "Ser tratada como gente": a vivência de mulheres atendidas no serviço de pré-natal de uma instituição filantrópica. São Paulo, 1996. 200p. Tese (Doutorado) - Escola de Enfermagem, Universidade de São Paulo.

2. FERRARI, M.; KALOUSTIAN, S.M. Introdução. In: KALOUSTIAN, S.M. (Org.) Família brasileira: a base de tudo. São Paulo, Cortez; Brasília, UNICEF, 1994. p.11-5.

3. MALDONADO, M. T.; CANELLA, P. A relação médico-cliente em ginecologia em obstetrícia. 2.ed. São Paulo : Roca, 1988.

4. QUINTERO VELASQUEZ, A.M. Cambios de la dinámica familiar durante la gestación y el posparto. Investigación y Educación en Enfermería. v.15, n.1, p.109-19, 1997.

5. RAMIRES, V.R. O exercício da paternidade hoje. Rio de J aneiro : Rosa dos Tempos, 1997.

6. REEDER, S.R. et al. Enfermería materno-infantil. Washington : Organización Panamericana de la Salud, 1978. 